\title{
ADVANCING THE ORANG ASLI THROUGH MALAYSIA'S CLUSTERS OF EXCELLENCE POLICY
}

\author{
Mohd Asri Mohd Noor ${ }^{\mathrm{a}}$ \\ Sultan Idris University of Education
}

\begin{abstract}
Since gaining independence in 1957, the government of Malaysia has introduced various programmes to improve the quality of life of the Orang Asli (aboriginal people). The Ministry of Education, for example, is committed in providing education for all including the children of Orang Asli. However, whilst the number of Orang Asli children enrolled in primary and secondary schools has increased significantly over the last decade, the dropout rate among them is still high. This has been attributed to factors such as culture, school location, poverty, pedagogy and many more. The discussion in this article is drawn upon findings from fieldwork study at an Orang Asli village in Johor, Malaysia. This article discusses efforts in raising educational attainment of the Orang Asli through the implementation of the Clusters of Excellence Policy. In so doing it highlights the achievement of the policy and issues surrounding its implementation at the site.
\end{abstract}

\section{Introduction}

Malaysia is one of the Newly Industrialised Countries (Bożyk, 2006) and ranks 28 in term of GDP per capita and 21 in term of ease of doing business (The World Bank, 2010). It is one of the most multi-ethnic and multi-religious countries in Southeast Asia (Brown, 2005) with a population of $28,717,780$ of which $65 \%$ are Bumiputeras ${ }^{1}, 26 \%$ Chinese, $8 \%$ Indians, and $1 \%$ other ethnic groups (Department of Statistics Malaysia, 2012). Whilst it is not the intent of this paper to engage in a detailed discussion of the history of Malaysia, even in the earlier works of key figures in the field of comparative and international education - such as Sadler (1900), Kandel (1933) and Hans (1959)there has been an emphasis on the importance of examining "educational phenomena within the broader socio-political contexts in which they occur" (Crossley, 2000, p. 321). Hence, in our attempt to understand the issues related to the education of Orang Asli (the indigenous minority of Peninsular Malaysia), context-including historical context-“does matter more than many policymakers and educational researchers realise" (Crossley, 2012, p. 8).

Prior to the colonisation period, much of the focus of education in Malaysia was on the inculcation of religious values and acquiring of skills vital for survival, such as fishing and farming for boys, and cookery and weaving for girls (Ministry of Education Malaysia (MoEM), 2009). Further education was obtained by devoting time as apprentices, living with a guru and learning various skills from the latter. By early nineteenth century, many pondok schools or madrasah (religious schools) were built by prominent Islamic scholars in the states of Kedah, Perak, Terengganu, Kelantan and Penang (MoEM, 2009).

a

Correspondence can be directed to: mohd.asri@fpe.upsi.edu.my

Journal of International and Comparative Education, 2012, Volume 1, Issue 2 ISSN 2232-1802 


\section{MOHD ASRI MOHD NOOR}

Although Christian missionary schools had been established during the colonisation period by the Portuguese, Dutch and British, they did not garner much response from the Malays, who feared that Christianity would influence their children.

The primary interest of the British during the earlier colonial period was commercial. To maximise the exploitation of Malayan resources profitably, the British adopted an 'open door' policy towards Chinese and Indian immigrants. This policy has lasting effects on the population structure of the country by polarising Malaya both in terms of ethnic disparities and class differences (Po-chu, 1999). This created problems closely linked with urbanisation, employment patterns and above all education (Watson, 1982, p. 92). Although the educational policies that developed in Malaya were largely defined by individuals on the spot rather than some kind of long-term Machiavellian colonial plans on the part of the British Government in Whitehall, nevertheless, there were a few constants that influenced these policies such as support for the Malay rulers, maintenance of the status quo for the Malay peasantry and relative indifference to the education of the immigrant groups (Watson, 1982, p. 105). Thus only a select few gained access to English schools and hence to lucrative and prestigious positions in government or in European firms. Consequently, two lines of education emerged. On the one hand, the Malay aristocrats received an elitist and English form of education, and on the other hand, the Malay peasants went to Malay schools. No consideration was paid to the education of the people of Chinese and Indian origin as they were regarded as transitory alien labourers without citizenship status or rights (Andaya \& Andaya, 1982; Bokhorst, 1993; Cheah, 2002). Similarly not much attention was paid to the education of Orang Asli as "western involvement was to some extent relatively superficial and hardly penetrated the hinterlands" (Watson, 2012, p. 34). Hence, when Malaysia gained its independence from Britain in 1957, the government was left with the difficult task of pulling the different groups in society together (Watson, 1982, p. 106).

\section{Education Development in Malaysia}

As pointed earlier, the school system inherited from the British was a divisive force in the Malaysian society since Malays, Chinese and Indians went to their respectively vernacular schools and the English schools were usually for the elites (Aziz \& Chew, 1980). Hence, educational efforts immediately after independence focused on forming a single system of national education and expanding the provision of basic education. The Razak Report of 1956 and Education Ordinance of 1957 were the two vehicles used to achieve the first objective. These two documents suggested the establishment of a national education system with the national language (Malay language) as the medium of instruction. A common curriculum for all schools was also suggested. The Rahman Talib Report in 1960 and the Education Act in 1961 on the other hand, greatly expanded basic education opportunities emphasising the 3Rs (reading, writing and arithmetic) basic education (MoEM, 2007). The 1961 Education Act also set a timetable to phase out English-medium schools and convert government-aided Chinese-medium secondary schools to Bahasa Melayu-medium secondary schools.

The racial riot of 13 May 1969 was a watershed in Malaysian history, which sent a clear message of the need to work on national unity. Following this-besides launching the New Economic Policy (NEP) - the government instituted a name change for the national language from Bahasa Melayu (Malay language) to Bahasa Malaysia (Malaysian language) so that the non-Malays would not regard this language as having a Malay identity (Asmah, 1987, p. 17). The incident also 
further emphasised the need to implement the Rahman Talib's recommendations without any more delays. Educational efforts of the government after the 13 May racial riots were geared towards eradicating poverty and restructuring the society by providing greater opportunities for the lower income and the Malay and other indigenous groups.

The 1990s saw fundamental education reforms in Malaysia partly due to the pressure from the global market. This period of the Malaysian history began with the declaration of Vision 2020, which envisaged Malaysia to become a developed nation in its own mould by 2020 (Prime Minister's Office of Malaysia, 2009). The introduction of the New Development Policy (NDP) replacing the NEP was aimed at continuing to achieve the objectives of promoting national integration and unity as well as providing greater opportunities for the Bumiputeras. The importance of education and training in the era of global competition is also stated in the NDP document:

Competitiveness, productivity, innovativeness and capability in management of new technologies in Malaysia will be determined by the quality of its human resources. [...] In view of the challenges ahead, Malaysians should be well equipped with a strong base in education and training. (Government of Malaysia, 2012)

The government's concern that Malaysia's education system must be improved so that the country can remain competitive in the global market is reflected in two significant bills passed by Parliament. The Education Act of 1996 has managed to buttress the national education system by incorporating pre-school, and public and private higher education into it. Hence, all preschool centres are now required to abide by the curriculum guidelines set by the Ministry of Education under the Education Act of 1996 (Siow \& Chang, 2011). The passing of the Private Higher Educational Institution Act, also in 1996, on the other hand, has increased the private sector's participation in tertiary education.

The new Millennium brought about yet another paradigm shift in teaching and learning. The emphasis in the new Millennium is on "the relevance of education to the future developments of individuals and their society" (Cheng, 2007, p. 74). This has brought about the notion of worldclass education. Malaysia realised that it needed to work hard to further develop its education system to produce ethical and knowledgeable human capital to meet this globalisation wave and the challenges of Vision 2020 (MoEM, 2006). Thus, the Education Development Plan 2001-2010 (EDP 2001-2010) was unveiled. In a nutshell, EDP 2001-2010 outlines four main thrusts which are to increase access to education, increase equity in education, increase quality of education, and improve the efficiency and effectiveness of education management with the aim of creating worldclass quality education system which will promote Malaysia as a centre of education excellence (MoEM, 2006). Although the Ministry of Education Malaysia (MoEM) is yet to achieve all the aims it set out, the EDP 2001-2010 has nevertheless provided an impetus for a further change in the education system to meet future challenges.

In accordance with the aspirations of the Rukunegara (National Ideology), National Education Philosophy, Vision 2020, and the EDP 2001-2010, the MoEM unveiled yet another "blueprint" - the Education Development Master Plan (EDMP) 2006-2010-on 16 January, 2006 to serve as a guide to provide focus, strategies, and implementation plans in ensuring the nation's 
education stays relevant in the future (MoEM, 2009). These are the principal thrusts that the government believes would help propel Malaysia into providing world-class education and becoming a centre of educational excellence.

In June 2012, the MoEM published its Interim Strategic Plan 2011-2020 as a continuation to the EDMP 2006-2010. In a nutshell, it aims at strengthening current initiative enablers to spur further change in the education system, and identifying new dimensions in achieving excellence in education quality (MoEM, 2012). However, the government admits that this will require amendments in the Education Act 1996.

Details of the development of education in Malaysia furnished above are necessary, as they provide evidence that the government of Malaysia is working tirelessly to improve access to, equity in and quality of education in Malaysia as a tool for national integration, to eradicate poverty and more recently to ensure that Malaysia is capable of producing human capital or resources that are able to meet the demands of the global market. Nevertheless, studies and available data have suggested that these efforts have not necessarily been beneficial for Orang Asli in general. Although the number of Orang Asli children enrolled in primary and secondary schools has increased significantly over the last decade, the dropout rate among them is still high. The following section, hence, discusses the education development of Orang Asli in Malaysia.

\section{Education Development of Orang Asli}

The Orang Asli of Peninsular Malaysia comprises of 18 ethnic subgroups classified under the Negrito, Senoi and Proto Malay (Nicholas, 2005). They make up only $0.6 \%$ of the total Malaysian population. Senoi is the largest ethnic group constituting about $55 \%$ of the total population of Orang Asli, followed by the Proto Malays and the Negritos at $42 \%$ and $3 \%$ respectively. According to the Annual Report of the Department of Orang Asli Development or JAKOA (formerly known as the Department of Orang Asli Affairs or JHEOA), in 2006, there were about 147,412 Orang Asli living mostly in Pahang and Perak (Department of Orang Asli Affairs, 2006). However, 76.9\% of the Orang Asli population remains below the poverty line. $35.2 \%$ is classified as living in hard-core poverty, compared to $1.4 \%$ nationally (Department of Statistics Malaysia, 2010). The national infant mortality rate is at 8.9 out of 1,000 live births, yet Orang Asli infant mortality rate is at a high of 51.7. The average life expectancy for Orang Asli is 53 years, compared to the national average of 73 years (Rusaslina, 2010).

Since independence, the government has embarked on a comprehensive development programme in efforts to develop the Orang Asli community. These developments can be classified into two types. The first is public development, which has impacts on the community. Education developments discussed in the previous section fall under this, at least in theory. The second is planned development specifically targeted for this community. For example, today there are about 869 Orang Asli villages throughout the country, $2 \%$ are located at the vicinity of existing townships, $61 \%$ in the outskirt of existing rural villages and $37 \%$ are in the remote areas (Mason \& Arifin, 2005). Some of them have been provided with and enjoyed modern facilities through the implementation of various development projects such as village resettlement programmes, rural roads, provision of electricity and water supply, social amenities, as well as access to education (Khor, 2001).

The JAKOA has been entrusted with the task of overseeing the development of the Orang Asli. Originally, the British formed the department in 1950-it was then known as the Department of Aborigines-to win the loyalty of the Orang Asli. Later in 1954, the government expanded the 
department and made it responsible primarily for enlisting Orang Asli in the government cause against the communists. The Aboriginal Peoples Act of 1954 gave the department control over all matters concerning Orang Asli (Asian Indigenous \& Tribal Peoples Network, 2008). In November 1961, the government made the department permanent, and all programmes concerning Orang Asli became its responsibility. One of the reasons for the single agency approach was that over $60 \%$ of the Orang Asli still lived in isolated areas, far from normal government services like education and medical care.

Education is the main agenda in the Orang Asli's development programmes and as a key mechanism in the effort to improve their quality of life (Mohd Tap, 1990). Prior to 1995, all educational programmes for the Orang Asli were run by the JHEOA. The department ran a threetiered educational programme aimed at preparing Orang Asli children to enter the national education system (Asian Indigenous \& Tribal Peoples Network, 2008; Kamarulzaman \& Osman, 2008):

1. The first three years of the inception of the programme, children went to village schools taught by JHEOA field staff;

2. Students who continued after three years went to central primary schools in larger Orang Asli communities where they could continue through primary six;

3. Students who passed their exams at the end of sixth grade could then go to normal government secondary schools in nearby rural or urban areas.

However, the educational programme managed by the JHEOA was a major failure (Ikram, 1997). The JHEOA field staffs were not formally trained and most of them had a low level of education themselves.

Furthermore, the Malay teachers supplied by the MoEM at the central primary schools lacked knowledge about the Orang Asli culture and tradition (Asian Indigenous \& Tribal Peoples Network, 2008). Surviving on financial assistance from JHEOA alone was not enough to maintain all the Orang Asli schools. These were some of the contributing factors towards the failure of the JHEOA educational programme. As the educational programme served to supplement rather than replace the national education system, thus whilst the teachers worked for and were paid by the JHEOA, the syllabus came from the MoEM.

Orang Asli children have been classified as a group of at-risk in the context of modernisation and hence face serious problems (Ministry of Education, 2006). Leaving the task of educating Orang Asli children to the JHEOA, however, did little to improve their condition. Realising this, the Malaysian government launched a policy that allocates special help to provide opportunities for equal footing, integrate them with the advanced section of the population, and protect their traditional beliefs (Ministry of Education, 2006). Part of this was done through the restructuring of the Orang Asli educational programme. In 1995, after a discussion with the relevant parties, it was decided that the best way to move forward was to allow all Orang Asli schools to be governed by the MoEM. Thus, under a Memorandum of Understanding (MOU) signed by the Ministry of Education and JHEOA, the MoEM took over the administration of all Orang Asli schools again, a situation that continues today.

Whilst there have been claims that the Malaysian government neglects the development of Orang Asli (see for example Tijah \& Joseph, 2003; Nicholas, 2005, 2006; Asian Indigenous \& Tribal Peoples Network, 2008; Rusaslina, 2010), these, however, are beyond the intent and scope of the

Journal of International and Comparative Education, 2012, Volume 1, Issue 2 
current paper. Rather, this paper intends to discuss an effort on the part of the MoEM in advancing the education of Orang Asli and their indigenous knowledge through the Clusters of Excellence Policy (CoEP) introduced in 2007.

\section{Clusters of Excellence Policy (CoEP)}

One of the core strategies in the EDMP 2006-2010 is to accelerate excellence in educational institutions through the establishment of school clusters based on their niche in academic, co-curricular and sport activities. This gave birth to the Clusters of Excellence Policy (CoEP). The CoEP proposed in the EDMP 2006-2010 is based on the government's belief that it is imperative to develop different approaches, standards, and performance indicators to help schools characterised by various types of diversity to achieve excellence (MoEM, 2006). In effect, the MoEM suggests that the 'one size fits all' approach is no longer appropriate for Malaysia. In a nutshell, the Policy envisages the selection of 300 schools from the various categories available in the country. These are excellent schools within their own categories with clear niche areas, which will then become models of excellence for other schools of the same type ${ }^{2}$. To achieve this, a move towards some degree of decentralisation in the form of guided-autonomy has been proposed.

When it was first proposed in April 2006, Orang Asli schools were somehow left out of the shortlisted schools. However, a directive from the Minister of Education in December 2006 had resulted in their inclusion in the clusters. The CoEP was implemented in mid-2007 with the announcement of 30 "excellent" schools inducted into the Clusters of Excellence. The idea is to allow these schools to further advance their niche areas through the allocation of a special fund and school-based management. Schools are required to first identify their niche areas and then prepare a request-for proposal (RFP) detailing how the funds will be used to further enhance their niche areas. The niche areas identified are both in academic and non-academic fields. To improve their performances in these niche areas, the schools are given autonomy in the areas of school management, human resource management, financial and physical resources management, curriculum management and implementation, and co-curricular management and implementation (MoEM, 2009). These aspects of guided autonomy allow the schools to, for example, introduce flexible working hours, hire consultants, external coaches and trainers, select suppliers, and offer academic subjects and co-curricular activities not available in other schools.

The remaining sections of this paper discuss the implementation of this policy at an Orang Asli school and its impact on advancing the Orang Asli children.

\section{Context Matters}

Henceforth, the discussion in this paper is driven by fieldwork findings of a case study involving an Orang Asli school in Johor-the southern-most state in West Malaysia. The study involved a series of interviews, observations and document reviews at the site. The participants included teachers, parents and students at the case-study school.

The case-study school was established on a piece of aborigines' reserved land with the aim of providing education for Orang Asli. It is not accessible to all because the two routes to the school are through an oil palm estate, which is privately owned. Visitors are required to produce relevant documents in order to gain passage. There is no properly paved road through the estate. The 
condition is even more unbearable during the monsoon season. When it was founded in 1963, the school was put under the administration of the Department of Aborigines (JOA) until 1966 when it was taken over by the MoEM and put under the administration of a nearby primary school. In 1975, the school's administration was returned to the newly renamed JHEOA under the watchful eye of its education unit. At the time, only one JHEOA teacher managed the school. However, in 1995, the school was officially handed back to the MoEM in line with the change in policy at the national level. The school finally received its first official head teacher in 1997. In 2001, the construction of the school's new buildings was started on a 10-acre land on the present site. This new concrete-building school boasts much better facilities than its predecessor.

The 299 hectares reserved land where the settlement and case-study school are located is populated by more than 300 people from 65 families of aborigines of the Jakun sub-ethnic group. Jakun is the second largest of the 18 sub-ethnic groups in Peninsular Malaysia. Most of the aborigines in Malaysia are animists. However, in the last 3 decades, Christian and Islamic missionaries have managed to persuade some to embrace Christianity and Islam.

At the case-study site, for example, 10 families-including that of the Tok Batin's (Orang Asli chief)-have embraced Islam as their new faith. Christianity is also flourishing with the establishment of two churches in the area. The Jakun language, which falls within the Malay Aboriginal languages, is the mother tongue of the people at the settlement. However, the national language is also widely used among the people, especially at official events.

Traditionally, the aborigines engaged in various forms of forest utilisation activities such as farming, gathering and hunting. However, in an effort to eradicate poverty among the aborigines, the government has regrouped most of them in settlements such as in the case-study site. Many have benefited through this development programme as they enjoy better facilities and living standards. As a result of their resettlement, most of the settlers at the case-study site are now involved in permanent agriculture such as rubber, oil palm, cocoa and fruit trees. Today, most of them are known to be wage earners. However, there is also a danger of the people losing their indigenous knowledge related to forest resource utilisation. At present for instance, there is only a handful in the community who are able to identify herbs and their special use.

The school is categorised as under subscribed. At the time of this case study, there were 29 boys and 24 girls studying in pre-school through year 6 in the school. There were 17 teachers and 3 non-academic staff in the school-9 female and 11 male. With the exception of the head and assistant head teachers who had a total of 50 years of experience between them, the majority of the teachers had less than 10 years of teaching experience, with 9 teachers having less than 5 years teaching experience.

\section{Advancing the Orang Asli through CoEP}

The niche areas selected by the case-study school are English language, aquatic and Orang Asli traditional culture and herbal medicines. The school believes that selecting English language as one of the niche areas gives it better chance to improve the level of English language competency among the students. The Orang Asli traditional culture and herbal medicines are chosen at the suggestion of the selection panel (MoEM Advisory Panel), while aquatic is included because the school's students are quite capable swimmers. Swimming in the nearby river has been part of the growing process of children at the case-study site. The inclusion of Orang Asli traditional culture and herbal medicines is significant as it allows the school to promote these to the younger generation and the outside world.

Journal of International and Comparative Education, 2012, Volume 1, Issue 2 
Activities to enhance the niche areas of the school require a huge sum of money. Evidently, the allocation of 150, 000 US Dollars as a special fund has helped the school tremendously. For example, in the English language niche area, one of the English teachers had devised an improvised 'snake and ladder' board game as a teaching and learning resource. A huge 'snake and ladder' board was produced on which pupils stood and moved according to the roll of a huge dice. At various stages, pupils had to complete tasks, such as naming an adjective beginning with the letter ' $d$ ', or risked the chance of rolling the dice when it was their next turn. The school had also managed to secure a total of 20 personal computers for the teaching and learning of English. Language camps involving students from other Orang Asli schools were also organised at the school compound.

Similarly, programmes to enhance pupils' skills in the Orang Asli traditional dance were taking place. Pupils practised at the village hall on weekends with the help of a few parents and two local teachers. According to these teachers, the school occasionally received assistance from professional trainers from one of the universities in the state. In the area of traditional herbal medicines, it was observed that some of the hundreds of medicinal herbal trees around the school bore the names of students who were in charge of caring for them. According to the pupils, they learnt the names of these trees and their usage from the late Pak Awi, who was a national expert in medical trees.

The aquatic niche area school's report noted that pupils had been taken to a public swimming pool in town twice every fortnight for training purposes. One of the biggest successes of this programme was in organising a swimming competition involving other Orang Asli schools in the district. The cost of the competition was borne by the case-study school. The competition provided other Orang Asli schools with the valuable experience of participating in such an event.

The impact of these activities is reflected in the improvement in students' performances. For example, there was an abrupt increase in the percentage of passes in the English language Primary School Assessment Test (UPSR) from $0 \%$ before the school was included in the Clusters of Excellence to $42.86 \%$ a year later. This, according to the school's teachers, is attributed to the various English language programmes that the school had organised using the special fund allocated to them. In swimming, a state level swimmer was born out of the many aquatic programmes carried out by the school. Students' performances in the Orang Asli traditional dance have been taken notice with invitations to perform in various state functions pouring in. Agencies such as MARDI (Malaysian Agricultural Research and Development Institute) and FRIM (Forest Research Institute Malaysia) have also expressed their interests in visiting and studying the hundreds of medicinal herbal trees available around the school.

\section{Challenges}

While the achievements described above have been attributed to the CoEP, it does not mean that the implementation of the initiative has been unproblematic. While admitting the potential of the cluster's concept, teachers criticised the sudden way in which the new policy was introduced. This means that teachers were ill-prepared to implement it in their school. Furthermore, when the MoEM announced its intention to create the Clusters of Excellence, the school community was not clear of its concept. Teachers' understanding at the initial stage of the implementation process was vague due to lack of information disseminated directly to them. Clarity, as suggested by Fullan (2007), is crucial in any educational change effort as without it 
teachers may not know what they need to do differently.

Although the case-study school eventually managed to select its niche areas, it is evident from interviews and document reviews that there was no in-depth deliberation on the choices of niche areas, and neither teachers nor parents were included in the decision-making process. As a result, teachers who are entrusted with the task of managing the niche areas believe that their voices have not been heard. This phenomenon is not uncommon in Malaysia as emphasised by Boey (2010), who claims that shared decision-making is still rare in Malaysian schools.

The exclusion of teachers in the selection of niche areas has created other problems. Some teachers believe that the school should be allowed to revise the niche areas selected with the possibility of dropping those that they are incapable of developing or enhancing. Enhancing the English language niche area, for example, has proved a formidable task. This is because English is the third language of the Orang Asli community. This can be seen in students' performances in the Primary School Assessment Test. Although the school had achieved $42.86 \%$ passes in the subject a year after it was inducted into the Clusters of Excellence, it is yet to achieve a better or similar result ever since.

In the case of aquatic niche area, it was found that pupils from the school do not frequent the river in the village anymore since it is now muddy and shallow due to rapid development. This was an oversight during the selection of swimming as a niche area. Some see this as a disadvantage while others see this as an opportunity to train pupils at the swimming pool to acclimatise them to the real competition situation. But to do so, teachers have to ferry students to the swimming pool in their own cars. This places the safety of the pupils in the hands of the teachers. It is also inconvenient when the teachers responsible for transporting the students are already overburdened with other responsibilities.

The death of Pak Awi, the person who was instrumental in identifying and maintaining the medicinal trees, has been a crippling blow to the school. This is because Pak Awi's wealth of knowledge had not been transferred to anyone else, not even his own son. Hence, the school is now in dire need of assistance from agencies such as MARDI and FRIM and individuals with the necessary expertise. Unfortunately, it is possible that this expertise does not exist as most of the trees around the school are only found locally.

Pupil absenteeism is another obstacle to the implementation of the initiative. Throughout the site visit period, it was observed that about 5 to 6 pupils were absent during the morning roll call. Every day, the on-duty teacher would have to seek these pupils at their homes. Sometimes, the teacher would have to wake the pupils and wait for them to get ready to go to school. Teachers believe lack of interest among parents and pupils means it is impossible to maintain high standards at the school. The same lack of commitment was observed during English night classes and cultural performance training sessions. Some parents blame their children's attitude saying that they have tried everything to make them go to school. While others, especially the parents of female pupils believe that education will not take them anywhere. Pupils, on the other hand, cite too much homework, strict teachers, uninteresting activities and tiredness as some of the reasons for staying away from school.

Another major obstacle to the advancement of niche areas is the lack of support provided to pupils once they leave their school. Teachers see this as the result of the failure of the policy to provide clear guidelines on students' future development once they have left primary school. Teachers claim that the lack of coordination among agencies both within and without the MoEM is 
responsible for the lack of post-primary support for students in the niche areas. Although the school managed to produce a state level swimmer through its aquatic niche area programme, it is most unfortunate to find out that the student had dropped out of his secondary school just a year later. When JHEOA had its education unit, the school was able to monitor the progress of its students because they were all under the purview of the Department. Now that the unit has been abolished, it is difficult as students have no one from the Department to monitor and guide them.

Teachers at the case-study school, echoing the intent of the MoEM, are committed in raising the educational attainment of Orang Asli. However, this is sometimes hampered by their lack of understanding of the nature and culture of Orang Asli. Studies have found that Orang Asli is a unique community adhering to their traditional system and beliefs. In the eyes of Orang Asli, learning is treated as a process to become a good person rather than competing for awards and certificates (Nicholas, 2005). Hence to Orang Asli, learning does not necessarily take place in schools. This is in total contrast to the national system of education, which places emphasis on fixed curriculum and exams results.

In another study, Abdul Razaq and Zalizan (2009) suggest that it is in the nature of Orang Asli children to be hyperactive. Orang Asli's traditional way of life-hunting and gathering in the jungle-is in their blood and thus contributes to this hyperactive behaviour. While it is easy to blame Orang Asli children for having short attention span in class (Kamarulzaman \& Osman, 2008), teachers-and the MoEM-sometimes fail to take notice of the contrast in the pedagogy when it comes to the education of Orang Asli. How can one expect Orang Asli children to sit through six hours of lessons a day when what is being taught is of little relevance to them?

The situation in the case-study site worsens especially since teachers live far away from the village, and thus are very much detached from the community as they only spend time at the school during weekdays from 8 in the morning till 2 in the afternoon. Although there is a block of quarters built for teachers at the case-study school, unfortunately, the six units available are left dilapidated without any takers. Teachers prefer to commute from the nearest town even though the journey takes almost one hour to complete. Of the total 17 teachers at the school, only 2 are Orang Asli.

\section{The Way Forward}

However, not everything is gloom and doom. The government of Malaysia must be applauded for taking steps in addressing the issues surrounding the well-being of Orang Asli especially in eradicating poverty, which has been identified as one of the major contributing factors that hinder their active participation and competition in the mainstream economic, social and political spheres (Nicholas, 2005; Asian Indigenous \& Tribal Peoples Network, 2008; Kamarulzaman \& Osman, 2008; Abdul Razaq \& Zalizan, 2009). Educational programmes, such as the Clusters of Excellence initiative, introduced by the MoEM have also contributed in improving the educational attainment of Orang Asli. There are also some encouraging signs in term of Orang Asli dropout rates. In 2008, the dropout rate of Orang Asli children at the primary level was $39.1 \%$. This has been significantly reduced to $29 \%$ in 2010 and $26 \%$ in 2011 . The MoEM is also working on to reduce this to $15 \%$ by 2015 . But there are still rooms for improvement, and it is heartening to see that the government is putting much effort into it.

On 21 June 2012, the government introduced seven initiatives in an effort to raise the educational attainment of Orang Asli (The Sun Daily, 21 June 2012). Under the Orang Asli Education 
Transformation Programme, the initiatives are listed as follows:

1. to strengthen administration at the school, district education office, state education department and ministry level;

2. to put elements of basic vocational education in lower secondary schools;

3. to reduce the dropout rate of Orang Asli students by 6 per cent each year;

4. to increase the intake of Orang Asli students for the Bachelor of Teaching Special Programme;

5. to improve the infrastructure for Orang Asli education;

6. to strengthen collaboration with strategic partners;

7. To create a performance detection system for schools and Orang Asli students.

By launching the Orang Asli Education Transformation Programme, the government intends to enhance the quality of leadership and management at all levels so that issues and problems of Orang Asli children can be resolved quickly. It is also encouraging to see that the MoEM acknowledges the need to take drastic action to reduce or if possible eliminate the dropout rate among Orang Asli children. Basic vocational education may be one of the ways to make education more relevant to Orang Asli children as it is a subject that they may be able to readily relate to.

As the number of Orang Asli teachers posted to Orang Asli schools is still small, the move to increase this is commendable as they are familiar with the culture, tradition and problems of Orang Asli children. Furthermore, they can become role models for the children and guide them to succeed. It is hoped that these initiatives coupled with the 7 million US Dollars that the government of Malaysia allocates annually for Orang Asli students will be the way forward in advancing Orang Asli.

\section{Conclusion}

Orang Asli have been living in isolation for many years. They have been deprived of proper education and health services. Nevertheless, the government of Malaysia has, since independence, allocated millions of dollars to improve their living condition. Various educational programmes have been devised in an effort to raise educational attainment of Orang Asli in Malaysia. For example, through CoEP the case-study Orang Asli school is provided with further financial assistance to help in their advancement. And more recently, the government announced its Orang Asli Education Transformation Programme to further improve the situation.

While financial assistance is much needed in advancing the Orang Asli, it is not the only critical success factor. The government may introduce various policies and programmes, or allocate millions of dollars for the purpose of Orang Asli education. But ultimately it requires the existence of enabling factors in order to succeed. A recent study by Tikly and Barrett (2010) suggests that a good quality education arises from interactions between three enabling environments: policy, the school, and the home and community. Hence, it is important that everyone involves is clear of the programmes and policies introduced by the government. Of no less importance, is the need to allow for stakeholders' engagement in policy formulation and implementation. This will not only overcome the 'implementation gap' between national policy and local level practice but also close 'the expectation gap' between the outcomes of education and what the communities expect education to deliver. With the involvement of and support from all, it is not impossible to advance the Orang Asli in Malaysia. 


\section{MOHD ASRI MOHD NOOR}

\section{Notes}

${ }^{1}$ Bumiputra is a noun used by the Malaysian government to collectively mean 'the sons of the soil' (Brown, 2005). The term not only refers to the Malays, but other indigenous groups such as the Negrito, Senoi, ProtoMalay, Penan, Iban, Bidayuh, Orang Ulu, Kadazandusun, Bajau and Murut (Andaya \& Andaya, 1982; Lee, 1999).

${ }^{2}$ Schools in Malaysia are classified into various types. These include: national primary schools (including Orang Asli schools), Chinese national-type primary schools, Tamil national-type primary schools, daily secondary schools, national-type secondary schools, residential schools, technical secondary schools, national religious secondary schools, premier schools, centennial schools, smart schools, special model schools, special education schools, and international and private schools

\section{References}

Abdul Razaq, A. \& Zalizan, M. J. (2009). Masyarakat Orang Asli: perspektif pendidikan dan sosiobudaya [Orang Asli community: education and sociocultural perspectives]. Bangi: Penerbit UKM.

Andaya, B. W. \& Andaya, L. Y. (1982). A history of Malaysia. Basingstoke: Macmillan Education Ltd. Asian Indigenous \& Tribal Peoples Network (2008). The Department of Orang Asli Affairs, Malaysia-an agency for assimilation. New Delhi: Asian Indigenous \& Tribal Peoples Network.

Asmah, O. (1987). Patterns of language communication in Malaysia. In O. Asmah (Eds.) National Language And Communication In Multilingual Societies. Kuala Lumpur: Dewan Bahasa dan Pustaka.

Aziz, A. A. \& Chew, T. Y. (1980). Malaysia. In N. T. Postlewaite and M. R. Thomas (Eds.) Schooling in the Asian Region. New York: Pergamon Press.

Boey, E. K. (2010). Teacher empowerment in secondary schools: A case study in Malaysia. Munchen: Herbert Utz Verlag GmbH.

Bokhorst, W. D. (1993). Malaysia: A study of language and education policy and state formation. Unpublished doctoral thesis. Ontario: University of Toronto.

Bożyk, P. (2006). Newly Industrialised Countries. Globalisation and the transformation of foreign economic policy. Aldershot: Ashgate Publishing Ltd.

Brown, G. (2005). Making ethnic citizens: the politics and practice of education in Malaysia. CRISE Working Paper No. 23. Oxford: Centre for Research on Inequality, Human Security and Ethnicity.

Cheah, B. K. (2002). Malaysia: the making of a nation. Singapore: Institute of South East Asian Studies.

Cheng, Y.C. (2007). Future developments of educational research in the Asia-Pacific region: Paradigm shifts, reforms, and practice. Educational Research for Policy and Practice, 6(2), 71-85.

Crossley, M. (2000). Bridging cultures and traditions in the reconceptualization of comparative and international education. Comparative Education, 36(3), 319-332.

Crossley, M. (2012). Comparative education and research capacity building: reflections on international transfer and significance of context. Journal of International and Comparative Education, 1(1), 4-12.

Department of Orang Asli Affairs. (2006). Annual report of Department of Orang Asli Affairs 2006. Kuala Lumpur: Jabatan Hal Ehwal Orang Asli.

101

Journal of International and Comparative Education, 2012, Volume 1, Issue 2 
Department of Statistics Malaysia (2010). Population and housing census of Malaysia 2010: Preliminary count report. Putrajaya: Department of Statistics Malaysia.

Department of Statistics Malaysia (2012). Population clock. Available at www.statistics.gov.my [Accessed 16 April 2012].

Fullan, M. (2007). The new meaning of educational change. New York: Routledge.

Government of Malaysia (2012). The New Development Plan. Available at www.epu.jpm.my [Accessed 20 June 2012].

Hans, N. (1959). Comparative education. London: Routledge and Kegan Paul.

Ikram, J. (1997). Kenyataan Ketua Pengarah Jabatan Hal Ehwal Orang Asli Malaysia pada perjumpaan dengan wakil-wakil media massa pada 31hb. Oktober, 1997. [Statement of the Director General of the Department of Orang Asli Affairs Malaysia at a meeting with mass media representatives on 31st. October, 1997]. Kuala Lumpur: Jabatan Hal Ehwal Orang Asli.

Kamarulzaman, K. \& Osman, J. (2008). Educational policy and opportunities of Orang Asli: A study of indigenous people in Malaysia. The Journal of Human Resource and Adult Learning, 4(1), 86-97.

Kandel, I.L. (1933). Studies in comparative education. Boston: Houghton and Mifflin.

Khor, G. L. (2001). Resettlement and nutritional implications: The case of Orang Asli in regroupment schemes. Pertanika Journal of Social Sciences and Humanities, 2, 123-132.

Lee, M. N. N. (1999). Education in Malaysia: towards vision 2020. School effectiveness and school improvement, 10(1), 86-98.

Mason, R. \& Arifin, S.M. (2005). The 'Bumiputera policy': Dynamics and dilemmas. Special issues of Orang Asli. Journal of Malaysian Studies, 21(1\&2), 315-329.

Ministry of Education Malaysia (2006). Pelan induk pembangunan pendidikan 2006-2010 [Education development master plan 2006-2010]. Putrajaya: Ministry of Education Malaysia.

Ministry of Education Malaysia (2007). Sejarah perguruan Malaysia. [The history of teaching in Malaysia]. Putrajaya: Ministry of Education Malaysia

Ministry of Education Malaysia (2009). Education in Malaysia: towards excellence. Putrajaya: Ministry of Education Malaysia.

Ministry of Education Malaysia (2012). Pelan strategik interim Kementerian Pelajaran Malaysia 2011-2020 [Ministry of Education Malaysia Interim Strategic Plan 2011-2010]. Putrajaya: Ministry of Education Malaysia.

Mohd Tap, S. (1990). Planning and administration of development programmes for tribal peoples (the Malaysian setting). Kuala Lumpur: Department of Orang Asli Affairs.

Nicholas, C. (2005). Integration and modernization of the Orang Asli: the impact on culture and identity. Paper presented at the 1st International Conference on the Indigenous People, 4-5 July 2005, Kuala Lumpur.

Nicholas, C. (2006). The state of Orang Asli education and its root problems. Orang Asli: rights, problems, solutions. A consultancy report prepared for the Human Rights Commission of Malaysia (SUHAKAM).

Po-chu, I. P. (1999). 'The making of modern Malaysia' - educational policy as a social engineering strategy designed to bring about an ideal Bangsa Malaysia. Unpublished M.A. thesis. UK:University of Leicester.

Prime Minister's Office of Malaysia (2009). The way forward - Vision 2020. Available at www.pmo.gov.my/?menu=page\&page=1904. [Accessed 10 July 2009].

Journal of International and Comparative Education, 2012, Volume 1, Issue 2 


\section{MOHD ASRI MOHD NOOR}

Rusaslina, I. (2010). Basic rights for the Orang Asli. Viewpoints. Singapore: Institute of South East Asia Studies.

Sadler, M. (1900). How far cam we learn anything of practical value from the study of foreign systems of education? In J.H. Hugginson (Ed.) Selections from Michael Sadler. Liverpool: Dejail and Meyorre.

Siow, H. L. \& Chang, L. H. (2011). Education in Malaysia: Development and transformation. In C. Brock \& L. P. Symaco (Eds.) Education in Southeast Asia. Oxford: Symposium Books.

The Sun Daily (21 June, 2012). DPM: Seven initiatives to transform Orang Asli education. Available at www.thesundaily.my/news/413573. [Accessed 1July 2012].

The World Bank (2010). Doing business Malaysia. Washington: World Bank and the International Finance Corporation.

Tijah, C. \& Joseph, J. (2003). Creating knowledge for change: a case study of Sinui Pai Sengik's educational work with Orang Asli communities in Malaysia. Asian South Pacific Bureau of Adult Education (ASPBAE).

Tikly, L. \& Barrett, A. M. (2010). A framework for education quality. EdQual Policy Brief No. 10. Bristol: EdQual.

Watson, K. (2012). Southeast Asia and comparative studies. Journal of International and Comparative Education, 1(1), 31-39.

Watson, K. (Eds.) (1982). Education in the Third World. Beckenham, Kent: Croom Helm Ltd. 